\title{
PUSAT PERBELANJAAN MODERN DI KECAMATAN PONTIANAK BARAT
}

\author{
Bimo Kurniawan Eka Sabarullah', Hamdil Khaliesh², Syaiful Muazir ${ }^{3}$ \\ ${ }^{1}$ Mahasiswa, Program Studi Arsitektur, Fakultas Teknik, Universitas Tanjungpura \\ kesbimo@gmail.com \\ ${ }^{2}$ Program Studi Arsitektur, Fakultas Teknik, Universitas Tanjungpura \\ ${ }^{3}$ Program Studi Arsitektur, Fakultas Teknik, Universitas Tanjungpura
}

Naskah diajukan pada: 16 Februari 2021

Naskah revisi akhir diterima pada: 18 Februari 2021

\begin{abstract}
Abstrak
Peningkatan penduduk dan perkembangan ekonomi di Kota Pontianak tiap tahunnya mengalami peningkatan, dan juga disalah satu kecamatan di Kota Pontianak yaitu Kecamatan Pontianak Barat yang tingkat perdagangan dan jasa yang lumayan tinggi. Untuk menindaklanjuti hal tersebut maka dibutuhkanlah sebuah wadah atau Pusat Perbelanjaan Modern di Kecamatan Pontianak Barat dengan memberikan ruang-ruang terbuka atau (open mall) sehingga dapat mewadahai kebutuhan konsumen sekaligus dapat menikmati ruang-ruang terbuka. Terdapat data-data sekunder yang memberikan pembahasan karakteristik mall, klasifikasi mall, dan teori-teori terkait pusat perbelanjaan modern. Pusat Perbelanjaan Modern di Kecamatan Pontianak Barat ini memberikan desain menarik dengan memberikan fasad solid dengan dua massa bangunan yang dihubungkan oleh sky bridge. Pusat Perbelanjaan Modern di Kecamatan Pontianak Barat ini berada dilokasi perdagangan dan jasa. Metode perancangan merupakan suatu tahapan yang sistematis, metode perancangan yang digunakan adalah metode J.C Jones dalam buku Metode Perancangan Arsitektur. Tahapan yang digunakan tahapan gagasan, informasi, analisis, sintesis, evaluasi, dan optimasi. Tujuan perancangannya adalah menghasilkan perancangan Pusat Perbelanjaan Modern di Kecamatan Pontianak Barat yaitu dapat mewadahi masyarakat di Kecamatan Pontianak Barat dengan memberikan area rekreasi dan hiburan dengan konsep Open Mall serta memberikan ruang-ruang untuk pengunjung mall seperti ritel pakaian dan aksesoris, ritel kuliner, ritel edukasi, ritel mainan, ritel tanaman, ritel olahraga, kegiatan indoor, dan kegiatan outdoor serta fungsi pendukung lainnya.
\end{abstract}

Kata-kata Kunci: Pusat perbelanjaan, Open mall, Sky bridge

\begin{abstract}
The increase in population and economic development in Pontianak City has increased every year, and it is also in one of the districts in Pontianak City, namely West Pontianak District, which has a fairly high level of trade and services. To follow up on this, we need a container or Modern Shopping Center in West Pontianak District by providing open spaces or (open malls) so that it can accommodate consumer needs as well as enjoy open spaces. There are secondary data that provide discussion of malls, mall classification, and theories related to modern centers. The Modern Shopping Center in West Pontianak District provides an attractive design by providing a solid facade with two masses of buildings served by a sky bridge. This Modern Shopping Center in West Pontianak District is located in a trade and service location. The design method is a systematic stage, the design method used is the J.C Jones method in the Architectural Design Methods book. The stages used are the stages of ideas, information, analysis, synthesis, evaluation, and optimization. The purpose of the design is to produce a design for a Modern Shopping Center in West Pontianak District, which is able to accommodate the community in West Pontianak District by providing recreational and entertainment areas with the concept of Open Mall and providing spaces for mall visitors such as clothing and accessories retail, culinary retail, educational retail, toy retail, plant retail, sports retail, indoor activities, and outdoor activities and other supporting functions.
\end{abstract}

Keywords: Shopping center, Open mall, Sky bridge 


\section{Pendahuluan}

Dikehidupan masyarakat ini pusat perbelanjaan merupakan salah satu yang utama dalam keseharian. Karena pusat perbelanjaan merupakan wadah kebutuhan berbelanja yang praktis dan mudah. Karena pusat perbelanjaan juga dijadikan prioritas dilingkungan masyarakat. Pada saat ini jumlah penduduk di Kota Pontianak yaitu sebanyak berjumlah 667.053 jiwa. Menurut data Badan Pusat Statistik Kota Pontianak (2018) Kecamatan Pontianak Barat Dalam Angka 2018 jumlah penduduk sebanyak 141.095 jiwa. Dari jumlah penduduk yang ada di Kecamatan Pontianak Barat, kepadatan rata-rata penduduk per kelurahannya sebesar 8.389 jiwa per km2.

Menurut Maitland (1985) pusat perbelanjaan yang berintikan satu atau beberapa departement store besar sebagai daya tarik dari retail-retail kecil dan rumah makan dengan tipologi bangunan seperti toko yang menghadap ke koridor utama mall atau pedestrian yang merupakan unsur utama dari sebuah pusat perbelanjaan (mall), dengan fungsi sebagai sirkulasi dan sebagai ruang komunal bagi terselenggaranya interaksi antar pengunjung dan pedagang. Semakin bertambahnya jumlah penduduk maka akan semakin tinggi dan meningkat pula barang-barang yang diperdagangkan, maka diperlukan luasan untuk kebutuhan pusat perbelanjaan.

Menurut Badan Pusat Statistik Kota Pontianak (2018) Kecamatan Pontianak Barat Dalam Angka 2018 PDRB menurut harga berlaku di Kecamatan Pontianak Barat pada setiap tahunnya mengalami peningkatan yakni pada tahun 2016 sebesar 4,2 triliyun rupiah dan pada tahun 2018 meningkat menjadi 5,1 triliyun rupiah. Sehingga distribusi persentase PDRB menurut lapangan usaha atas dasar harga berlaku pada tahun 2018 terdapat sektor dominan yang berpengaruh terhadap pembentukan PDRB yaitu, sektor Perdagangan besar dan Eceran sebesar 24,58 persen.

Untuk pusat perbelanjaan bukan hanya sebuah pusat perbelanjaan yang melakukan proses jual beli melainkan terdapat area rekreasi dan hiburan sebagai sarana penunjang, saat ini di Kota Pontianak belum adanya sebuah pusat perbelanjaan yang menerapkan hal tersebut. Dan juga permasalahan umum yang terdapat pada kasus-kasus pusat perbelanjaan yang ada di Kota Pontianak dan sekitarnya yaitu minimnya lahan parkir, kurangnya area rekreasi, dan akses masuk dan keluar yang menyebabkan macet dikarenakan jalan kurang lebar.

Dari penjelasan latar belakang tersebut dapat kita simpulkan permasalahan yaitu kebutuhan penduduk, ekonomi meningkat, tidak terdapatnya pusat perbelanjaan modern, tidak adanya area rekreasi dan peruntukan lahan menurut RTRW sehingga berpengaruh terhadap kebutuhan masyarakat juga sehingga diperlukanlah sebuah pusat perbelanjaan.

\section{Kajian Pustaka}

Berdasarkan Peraturan Presiden Republik Indonesia Nomor 112 Tahun 2007 Tentang Penataan Dan Pembinaan Pasar Tradisional Pusat Perbelanjaan Dan Toko Modern menyebutkan bahwa pusat perbelanjaan adalah suatu area tertentu yang terdiri dari satu atau beberapa bangunan yang didirikan secara vertikal dari satu atau beberapa bangunan yang didirikan secara vertikal maupun horizontal, yang dijual atau disewakan kepada pelaku usaha atau dikelola sendiri untuk melakukan kegiatan perdagangan barang.

Menurut Maitland (1985) mall adalah pusat perbelanjaan yang berintikan satu atau beberapa departement store besar sebagai daya tarik dari retail-retail kecil dan rumah makan dengan tipologi bangunan seperti toko yang menghadap ke koridor utama mall atau pedestrian yang merupakan unsur utama dari sebuah pusat perbelanjaan, dengan fungsi sebagai sirkulasi dan sebagai ruang komunal bagi terselenggaranya interaksi antar pengunjung dan pedagang.

Suatu wadah dalam masyarakat yang menghidupkan kota atau lingkungan setempat. Selain berfungsi sebagai tempat untuk kegiatan berbelanja atau transaksi jual beli, juga berfungsi sebagai tempat untuk berkumpul atau berekreasi (Marlina, 2008). 
Menurut Rubenstain (1978) mall dalam berbagai topik sering disamakan dengan shopping centre, sehingga dalam berbagai sumber literatur, klasifikasi mall hampir sama dengan klasifikasi shopping center.

Tabel 1. Karakteristik bentuk pusat perbelanjaan

\section{Karateristik Berdasarkan Fisik}

\section{Skema}

Open Mall (Mal Terbuka) merupakan mall terbuka atau biasa dengan disebut shopping plaza adalah pusat perbelanjaan terbuka dengan deretan unit-unit retail pada umumnya terdiri dari 1-2 lantai yang bersusunan sejajar (berderet lurus maupun membentuk konfigurasi (U atau L)

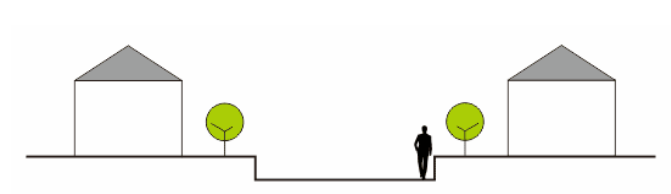

Open Mall

Closed Mall merupakan mall tipikal pusat perbelanjaan yang bersifat tertutup / indoor yang berisi unit-unit retail dan pada umumnya disewakan

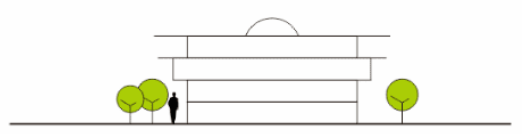

Closed Mall

Sumber: Rubenstain, 1978

Perancangan mall berdasarkan aspek struktural yang juga meliputi konstruksi dalam pembangunan mall. Sesuai dengan Peraturan Menteri Pekerjaan Umum Nomor 29/PRT/M/2006 Tentang Persyaratan Teknis Bangunan dan Gedung, dijelaskan bahwa mall termasuk bangunan kelas 6 dan ada beberapa persyaratan mengenai struktur bangunan komersial sebagai berikut :

1. Jarak struktur utama dari tapak sekurang-kurangnya $10 \mathrm{~m}$ ke dalam tapak

2. Bangunan dengan bentuk dasar $\mathrm{T}, \mathrm{L}$ dan $\mathrm{U}$ hendaknya menggunakan dilatasi pada $25 \mathrm{~m}$ untuk mencegah kerusakan akibat gempa

3. Saat terjadi gempa, struktur bangunan harus dapat bertahan dalam waktu yang cukup bagi pengguna untuk melarikan diri,

Standar layout ruang mengacu kepada buku Data Arsitek menurut (Neufert, 1992) yang sesuai dengan ruang-ruang Pusat Perbelanjaan Modern.

Tabel 2. Layout besaran ruang pusat perbelanjaan

\begin{tabular}{ccccc}
\hline Nama Ruang & Standar Luas & Sumber & Gambar \\
\hline Departement Store & $300-500 \mathrm{~m} 2$ & Data Arsitek & \\
\hline Retail & $\begin{array}{c}50-100 \text { unit skala } \\
\text { regional/grid }\end{array}$ & Data Arsitek & \\
\hline
\end{tabular}




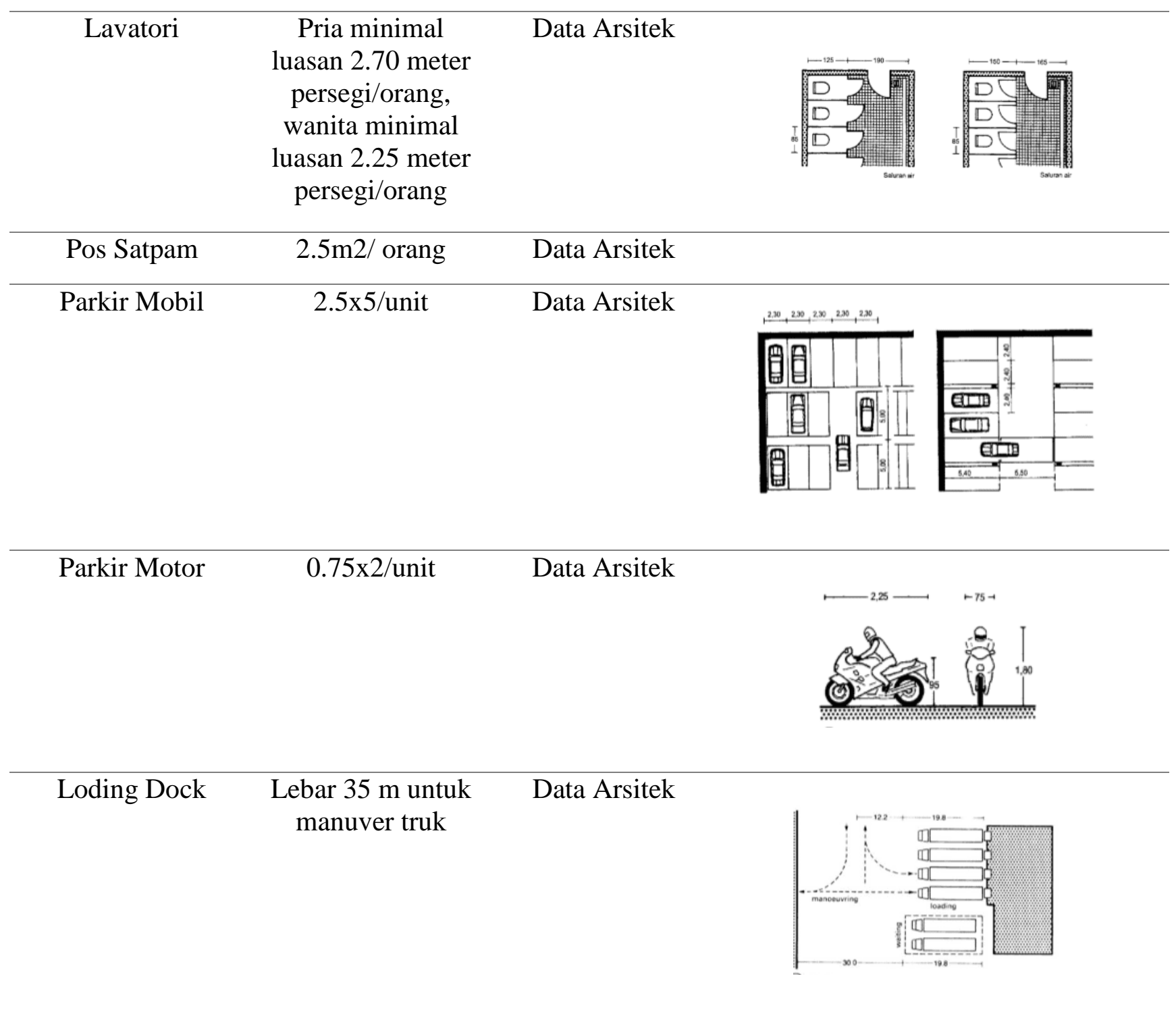

\section{Sumber: Neufert, 1992}

Menurut Haryono (1978) rekreasi merupakan bersifat luwes atau fleksibel ini berarti rekreasi tidak dibatasi oleh tempat, ataupun fasilitas dan alat tertentu. Alat dan fasilitas adalah sarana yang mendukung berlangsungnya kegiatan rekreasi.

Menurut Fairchild (1994) rekreasi adalah semua kegiatan yang dilakukan pada waktu senggang baik secara individual maupun secara bersama yang bersifat bebas dan menyenangkan, sehingga orang cenderung untuk melakukannya. Rekreasi meliputi pertandingan olahraga, santai, dan hobi. Rekreasi merupakan suatu kegiatan khusus yang ditentukan oleh elemen waktu, kondisi dan sikap seseorang dan lingkungannya.

\section{Metode}

Metode perancangan Pusat Perbelanjaan Modern di Kecamatan Pontianak Barat mengacu kepada metode perancangan menurut J. C. Jones yang terdiri dari beberapa tahap yaitu gagasan, informasi, analisisi, sintesis, evaluasi, dan optimalilasi dalam Nuraini (2010). Pada tahap gagasan diawali dengan menentukan sebuah judul perancangan yaitu "Pusat Perbelanjaan Modern di Kecamatan Pontianak Barat", dengan menjabarkan sebuah gagasan yang menjadikan latar belakang perancangan, kemudian merumuskan masalah, tujuan perancangan, sasaran perancangan, manfaat 
perancangan dan lingkup perancangan. Pada tahap informasi, mencari dan memaparkan data. Data terdiri dari dua jenis, yaitu primer dan sekunder. Data primer yaitu data tapak perancangan Pusat Perbelanjaan Modern di Kecamatan Pontianak Barat, sedangkan data sekunder yaitu teori-teori yang diperoleh dari literatur-literatur tentang Pusat Perbelanjaan Modern. Tahap analisis, berupa analisis internal, eksternal, bentuk, struktur, utilitas, dan fisika bangunan pada perancangan Pusat Perbelanjaan Modern di Kecamatan Pontianak Barat. Tahap Sintesis berupa perumusan konsep perancangan Pusat Perbelanjaan Modern hasil pada tahapan analisis sebelumnya. Tahap evaluasi berupa rancangan skematik pada perancangan Pusat Perbelanjaan Modern. Tahap optimalisasi berupa pengaplikasian dan pengoptimalisasikan konsep Pusat Perbelanjaan Modern terhadap gambar denah, tampak, potongan dan lain lain.

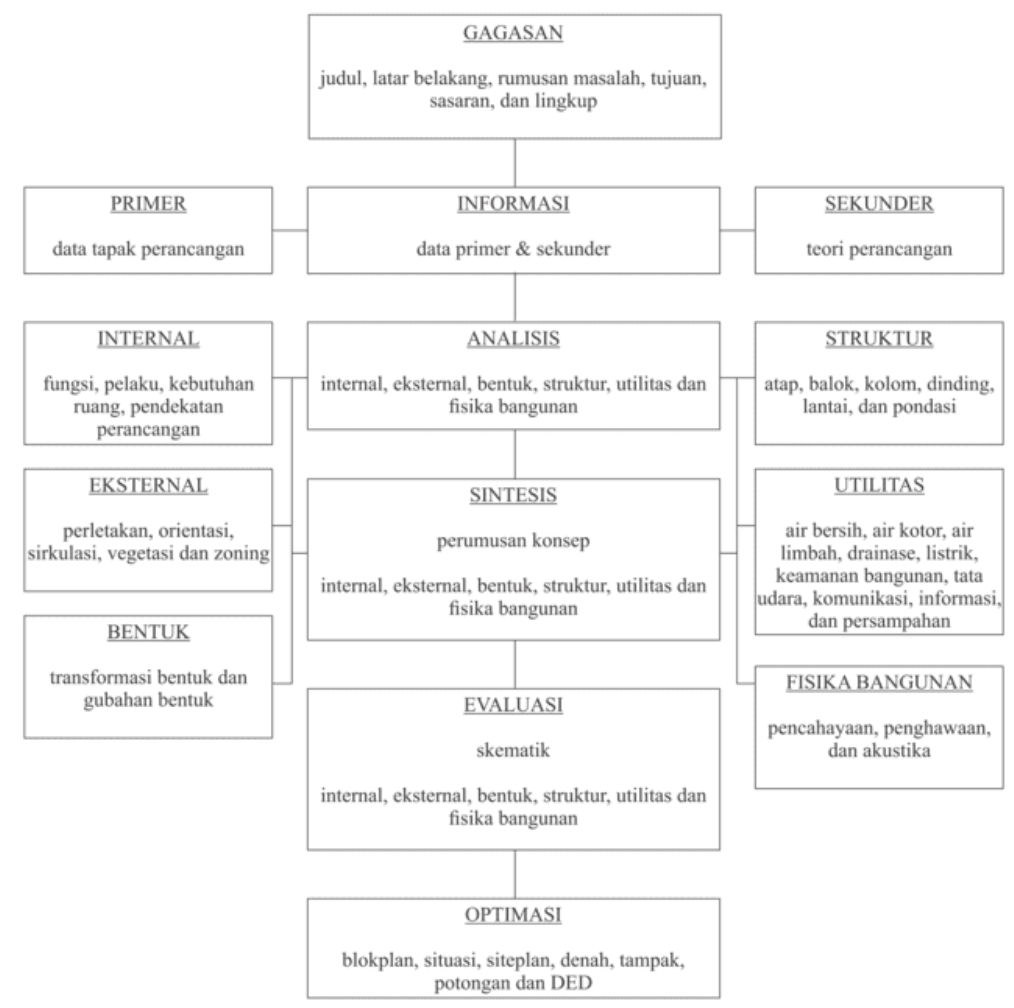

Gambar 1. Proses perancangan

Sumber: Penulis, 2021

\section{Hasil dan Pembahasan}

Hasil dan pembahasan meliputi penjabaran terhadap konsep-konsep yang telah digunakan berdasarkan hasil analisis-analisis yang menghasilkan produk rancangan yang terdiri dari landasan konseptual dan konsep perancangan. Pada landasan konseptual membahas tentang analisis internal dan analisis eksternal. Kemudian, pada konsep perancangan membahas konsep bentuk, konsep stuktur, konsep utilitas, konsep fisika bangunan dan hasil perancangan berupa masterplan, denah, tampak, potongan, dan perspektif dalam dan luar bangunan.

\section{Landasan Konseptual}

\section{Internal}

Pusat Perbelanjaan Modern di Kecamatan Pontianak Barat merupakan suatu wadah perbelanjaan yang dapat memberikan kebutuhan masyarakat dengan menyediakan ritel-ritel seperti ritel pakaian dan aksesoris, ritel kuliner, ritel edukasi, ritel mainan, ritel tanaman, ritel olahraga, kegiatan indoor, dan kegiatan outdoor untuk pengunjung Pusat Perbelanjaan Modern ini. Tujuan dari Pusat Perbelanjaan Modern di Kecamatan Pontianak Barat ini yaitu suatu tempat yang dapat 
mewadahi masyarakat di Kecamatan Pontianak Barat dan sekitarnya dengan memberikan area rekreasi dan hiburan.

Pendekatan perancangan pusat perbelanjaan modern ini akan menggunakan pendekatan pola penataaan retail-retail yang dimana tiap-tiap retail akan dibedakan ukuran, warna, dan kapasitas berdasarkan tipe retailnya, Open Mall (Mal Terbuka) merupakan mal terbuka atau biasa dengan disebut shopping plaza adalah pusat perbelanjaan terbuka dengan deretan unit-unit retail pada umumnya terdiri dari 1-2 lantai yang bersusunan sejajar (berderet lurus maupun membentuk konfigurasi U atau L (Rubenstain, 1978).

Analisa Struktur bangunan yakni terkait dengan sub structure (struktur bawah) bangunan, ipper structure (struktur atas) bangunan. Pada struktur pondasi terdapat permasalahan pada tapak yakni kondisi lahan yang gambut dan memiliki kedalaman tanah keras yang cukup dalam lebih dari 8 meter di dalam tanah, menyikapi permasalahan tersebut maka haruslah menganalisis lebih lanjut tentang pemilihan jenis pondasi, rancangan bangunan merupakan bangunan dengan fungsi perbelanjaan yang direncanakan berjumlah empat lantai dengan kondisi tanah site yang letak tanah kerasnya lumayan dalam. Opsi pemilihan pondasi tiang pancang (timber pile, concrete pile, dan steel pile).

Untuk struktur atas Pemilihan sistem struktur rangka badan didasari oleh kebutuhan ruang yang tidak memiliki area-area bebas kolom yang cukup lebar (bentang lebar) sehingga sistem struktur yang dipilih yakni rangka kaku/ rigid. Opsi pemilihan struktur atas yaitu rangka baja.

Analisis utilitas mencakup sistem air bersih, sistem pembuangan air kotor dan kapasitas air bersih maupun sanitasi, jaringan listrik dan pengkabelan, keamanan terhadap kebakaran, tata udara (HVAC), informasi dan komunikasi, penangkal petir, keamanan bangunan, dan transportasi bangunan. Menurut Juwana (2005) pada umumnya pasokan air bersih pada bangunan dapat menggunakan dua sistem yaitu sistem pasokan ke atas (up feed) dan sistem pasokan ke bawah (down feed).

\section{Eksternal}

Lokasi perancangan pertama berada pada Jalan Komodor Yos Sudarso, Kelurahan Sungai Beliung, Kecamatan Pontianak Barat, Kota Pontianak, Kalimantan Barat. Lokasi tapak merupakan zona perdagangan dan jasa dengan luasan site $\pm 35.000 \mathrm{~m} 2$ dengan $\mathrm{KDB}$ maksimal $80 \%$, KDB $60 \%$, $\mathrm{KDH} 40 \%$, GSB yaitu 5 meter dan memiliki jalan dengan lebar 10 meter dengan material semen. Lokasi tapak juga berada didekat area perdagangan, permukiman, sekolah, dan masjid sehingga menjadi potensi terhadap lokasi tapak.
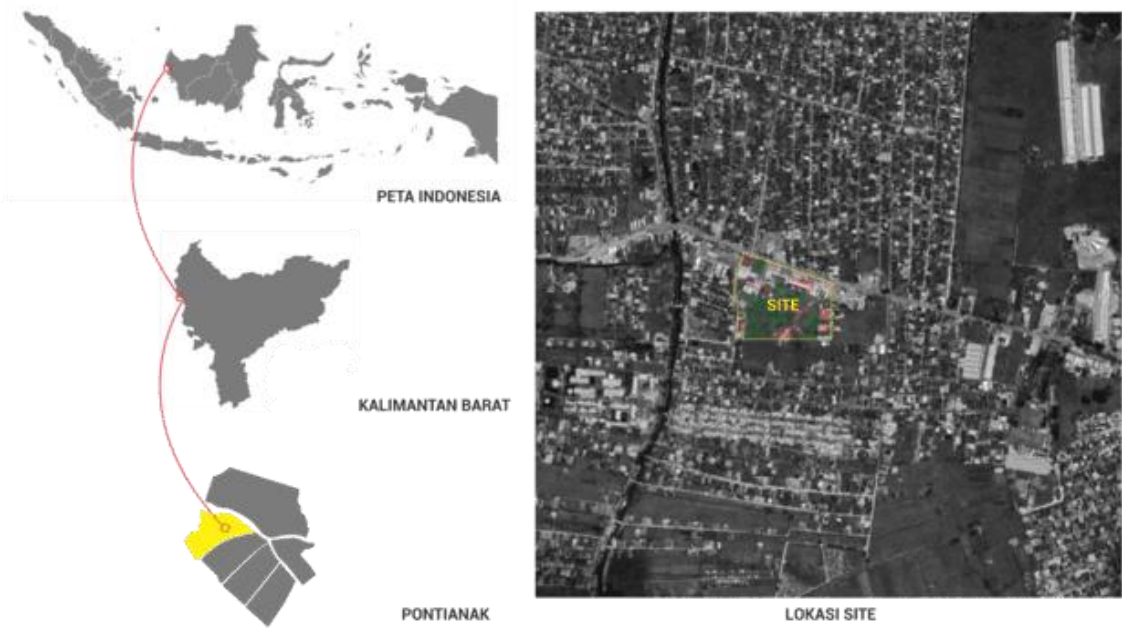

Gambar 2. Lokasi perancangan Pusat Perbelanjaan Modern di Kecamatan Pontianak Barat Sumber: Penulis, 2021 
Pada lokasi perancangan akan memasuki tahapan analisis yaitu terdiri dari analisis perletakan, analisis orientasi, analisis sirkulasi, analisis vegetasi dan analisis zoning yang akan dijabarkan sebagai berikut:
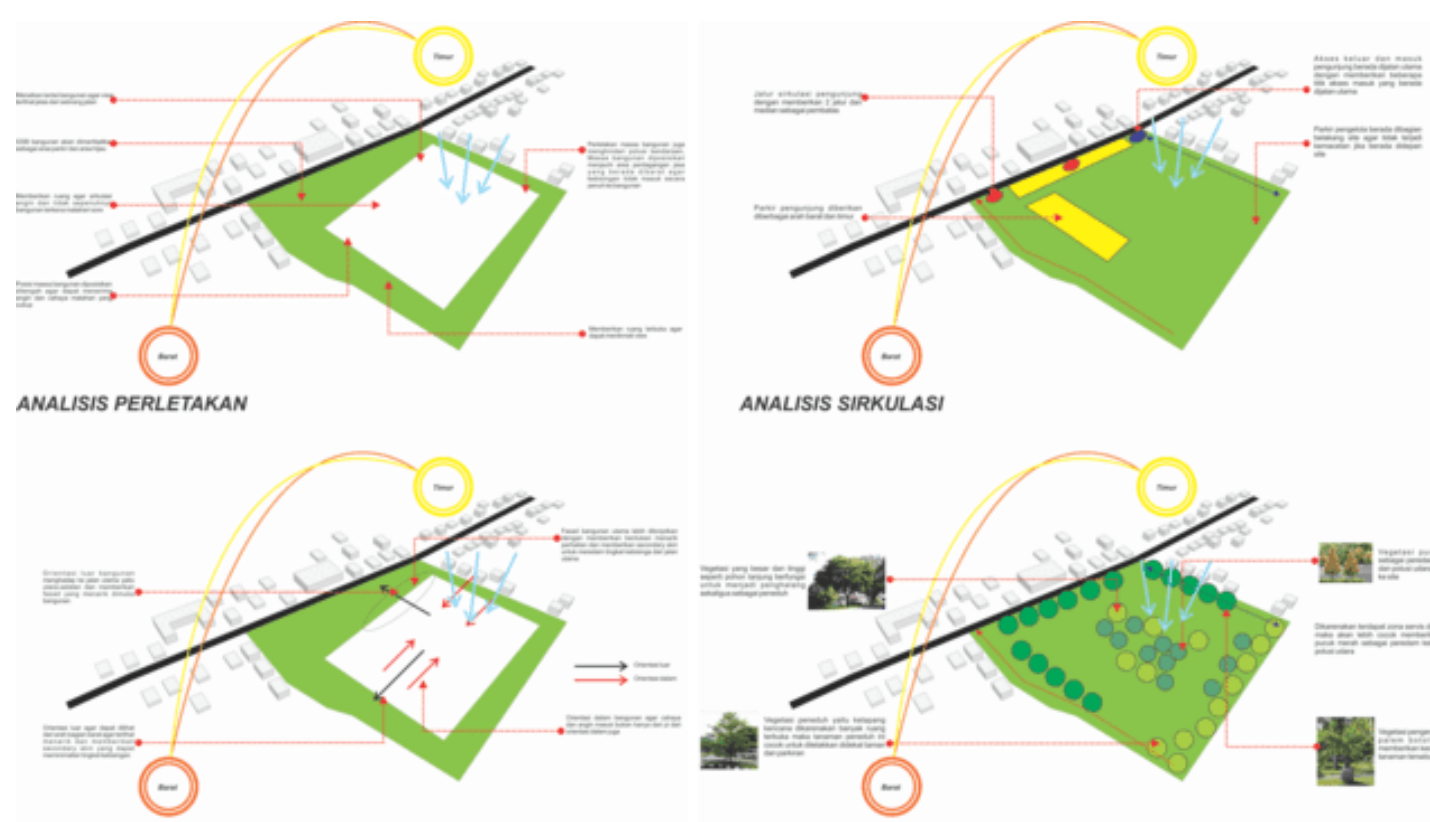

ANALISIS SIRKULASI

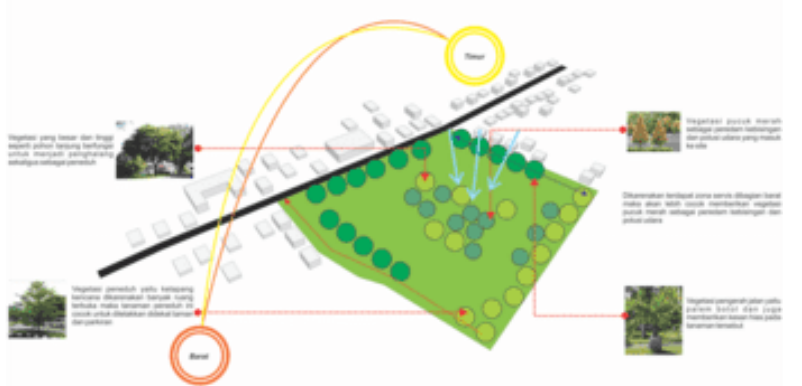

ANALISIS ORIENTASI

ANALISIS VEGETASI

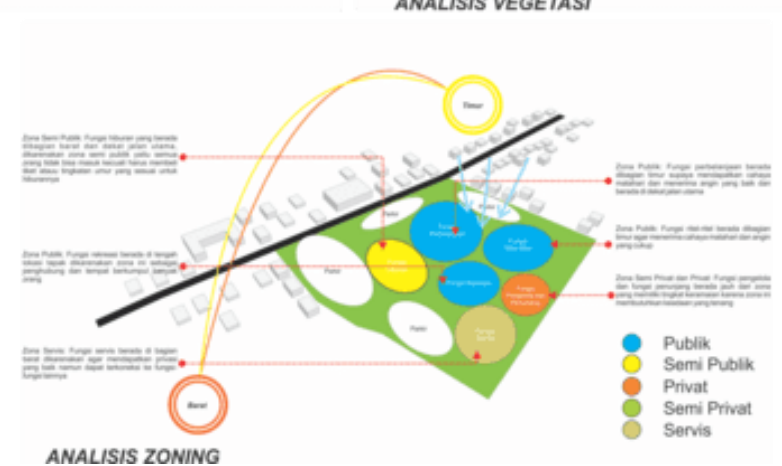

Gambar 3. Konsep tapak perancangan Pusat Perbelanjaan Modern di Kecamatan Pontianak Barat Sumber: Penulis, 2021 


\section{Konsep Perancangan}

\section{Konsep Bentuk}

Analisis bentuk bangunan dilihat dari bentuk secara makro pada perancangan Pusat Perbelanjaan Modern di Kecamatan Pontianak Barat, bentuk awal bangunan yaitu persegi panjang.
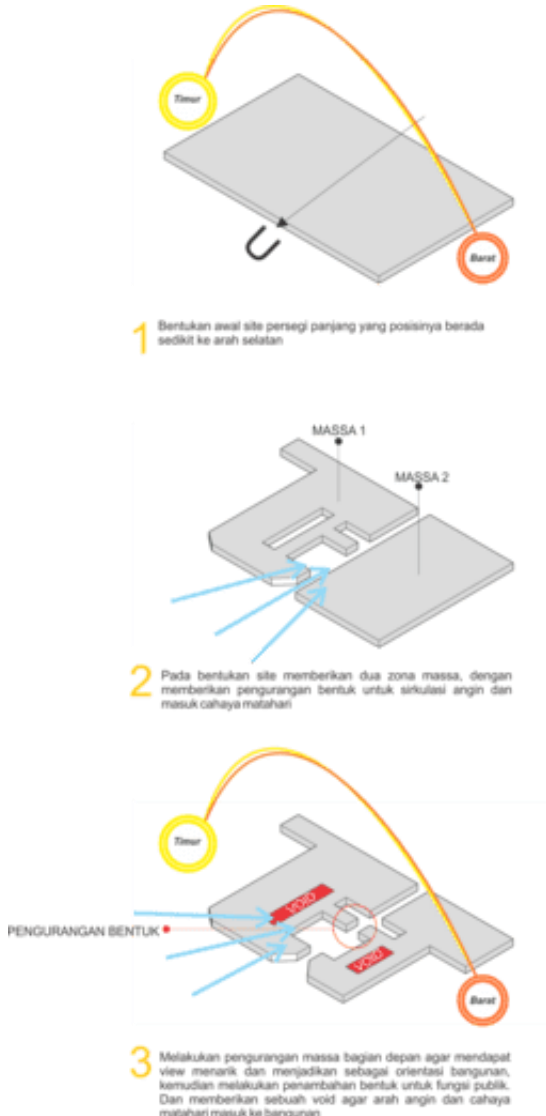
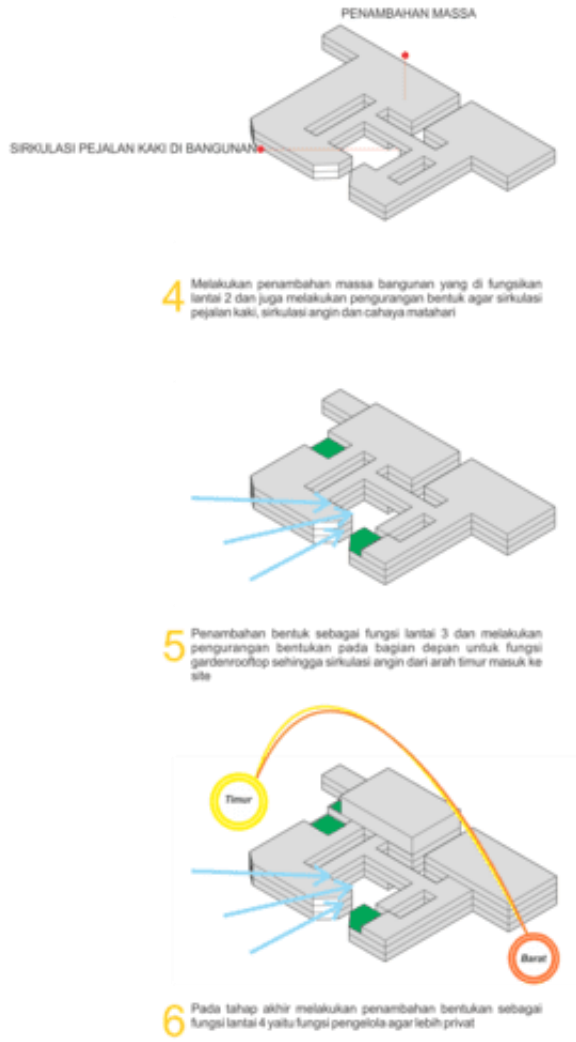

Gambar 4. Analisis bentuk bangunan Pusat Perbelanjaan Modern di Kecamatan Pontianak Barat Sumber: Penulis, 2021

\section{Konsep Struktur}

Struktur bangunan pusat perbelanjaan modern ini sangat mempengaruhi oleh kebutuhan ruang dan fungsinya. Untuk bentang dan modul pada struktur pusat perbelanjaan modern ini tidak rumit dan pemilihan bahan bangunan juga dibagi menjadi struktur bawah (sub structure) dan struktur atas (upper structure). Untuk struktur atas (upper structure) menggunakan rangka atap baja profil dikarenakan pertimbangan lebin kuat, tidak karatan, dan dapat digunakan untuk bentang lebih dari 8 meter. Jenis rangka atap yang digunakan yaitu atap dak beton dengan kemiringan 1 derajat dan menggunakan jenis atap kupu-kupu yang cocok untuk lokasi setempat. Jenis struktur balok, kolom, dan plat lantai menggunakan beton dikarenakan memiliki ketahanan yang kuat dan tahan terhadap api. Untuk dinding menggunakan material bata ringan dan dinding partisi untuk retail-retail dikarenakan memiliki kemudahan dalam pelaksanaan.

Struktur bawah bangunan menggunakan jenis pondasi tiang pancang yang cocok di daerah Kota Pontianak yang memiliki struktur tanah rawa dengan muka air tanah tinggi dan daya dukung tanah yang rendah. Pondasi tiang pancang beton memiliki kelebihan yaitu daya tahan yang kuat dan proses pengerjaan langsung di tempat.

\section{Konsep Utilitas}

Jaringan air bersih sudah dianalisa sebelumnya jaringan air bersih menggunakan system upfeed yang mendapatkan sumber air bersih dari PDAM. Jaringan air kotor berupa pipa-pipa yang 
akan diletakkan didalam shaft air kotor sehingga dimudahkan distribusinya, sebelum menuju ke roil kota air kotor akan melewati STP (Sewage Treatment Plant) seperti skema berikut:

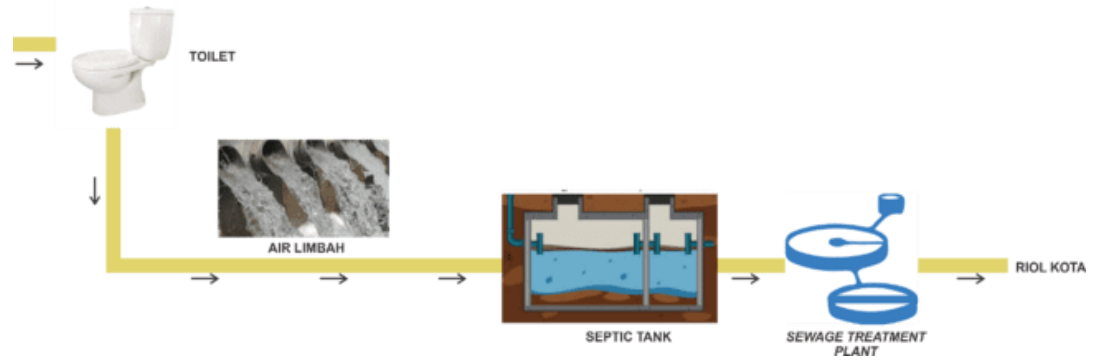

Gambar 5. Skema Sewage Treatment Plant Sumber: Penulis, 2021

Pusat Perbelanjaan Modern juga memerlukan sistem proteksi kebakaran pada kawasan tersebut yaitu hydrant halaman dengan jarak radius 40 meter. Kemudian didalam bangunan menggunakan PAR (Pemadam Api Ringan), sprinkler, hydrant box dan smoke detector.

Sumber energi listrik pada bangunan ini berasal dari PLN dan genset yang fungsinya sebagai sumber energi listrik cadangan.

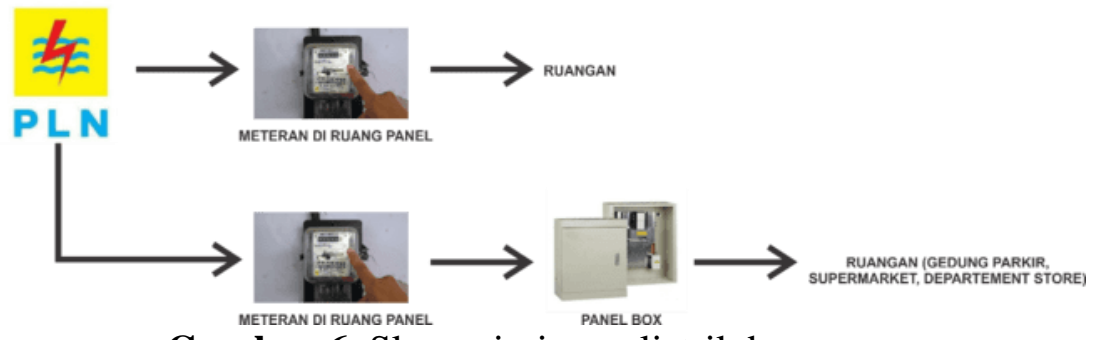

Gambar 6. Skema jaringan listrik bangunan

Sumber: Penulis, 2021

\section{Konsep Fisika Bangunan}

Fisika bangunan pada Pusat Perbelanjaan Modern di Kecamatan Pontianak Barat terdiri dari 3 aspek yaitu pencahayaan, penghawaan, dan akustika bangunan. Dari masing-masing aspek tersebut dijabarkan menjadi alami (memanfaatkan kondisi iklim).

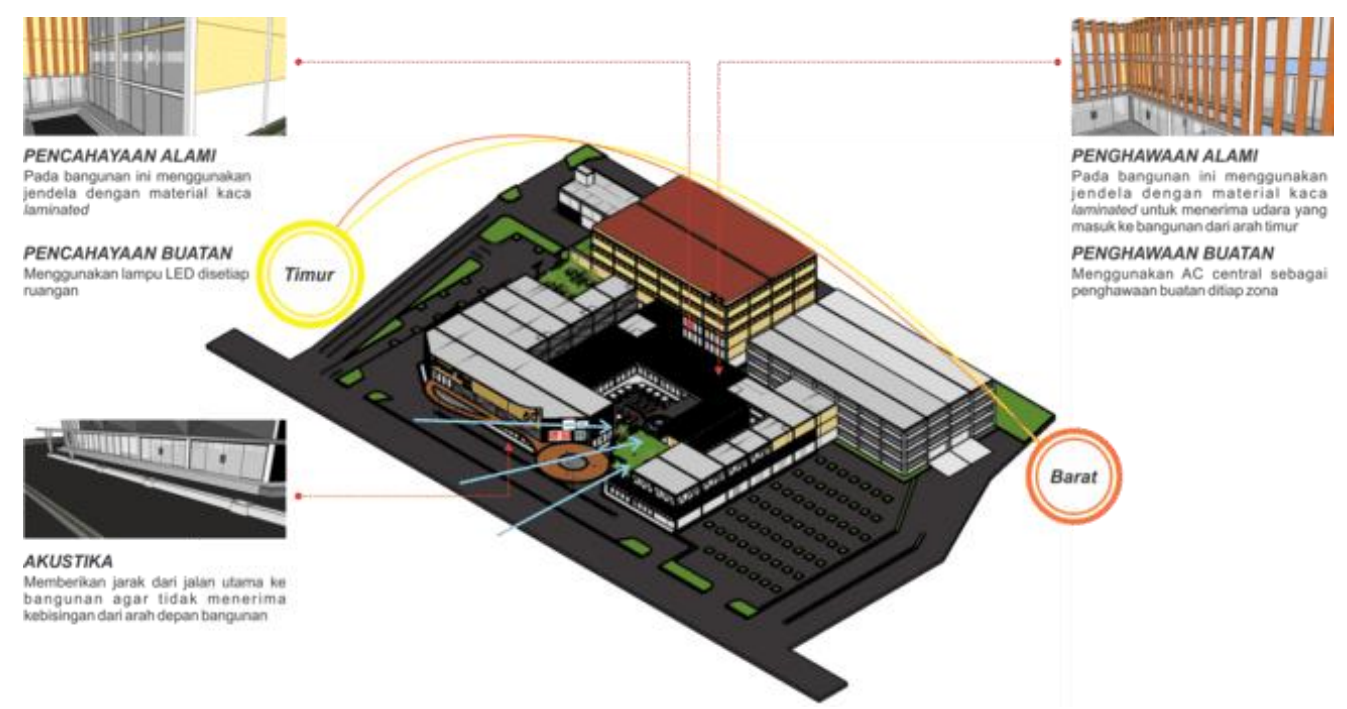

Gambar 7. Konsep fisika bangunan

Sumber: Penulis, 2021 


\section{Hasil Perancangan}

Pusat Perbelanjaan Modern di Kecamatan Pontianak Barat berada dijalan Komodor Yos Sudarso dengan luasan 35.000 meter persegi dengan Fungsi dari perancangan ini sudah disinggung pada latar belakang, perancangan pusat perbelanjaan modern ini menggunakan konsep terbuka. Dengan merancang memanfaatkan tengah site sebagai area terbuka untuk pengunjung agar memberikan daya tarik dan meningkatkan kemajuan pada pusat perbelanjaan ini untuk kedepannya. Perancangan pusat perbelanjaan modern ini menerapkan beberapa fungsi seperti fungsi perbelanjaan, fungsi pendukung, fungsi pengelola dan fungsi servis.
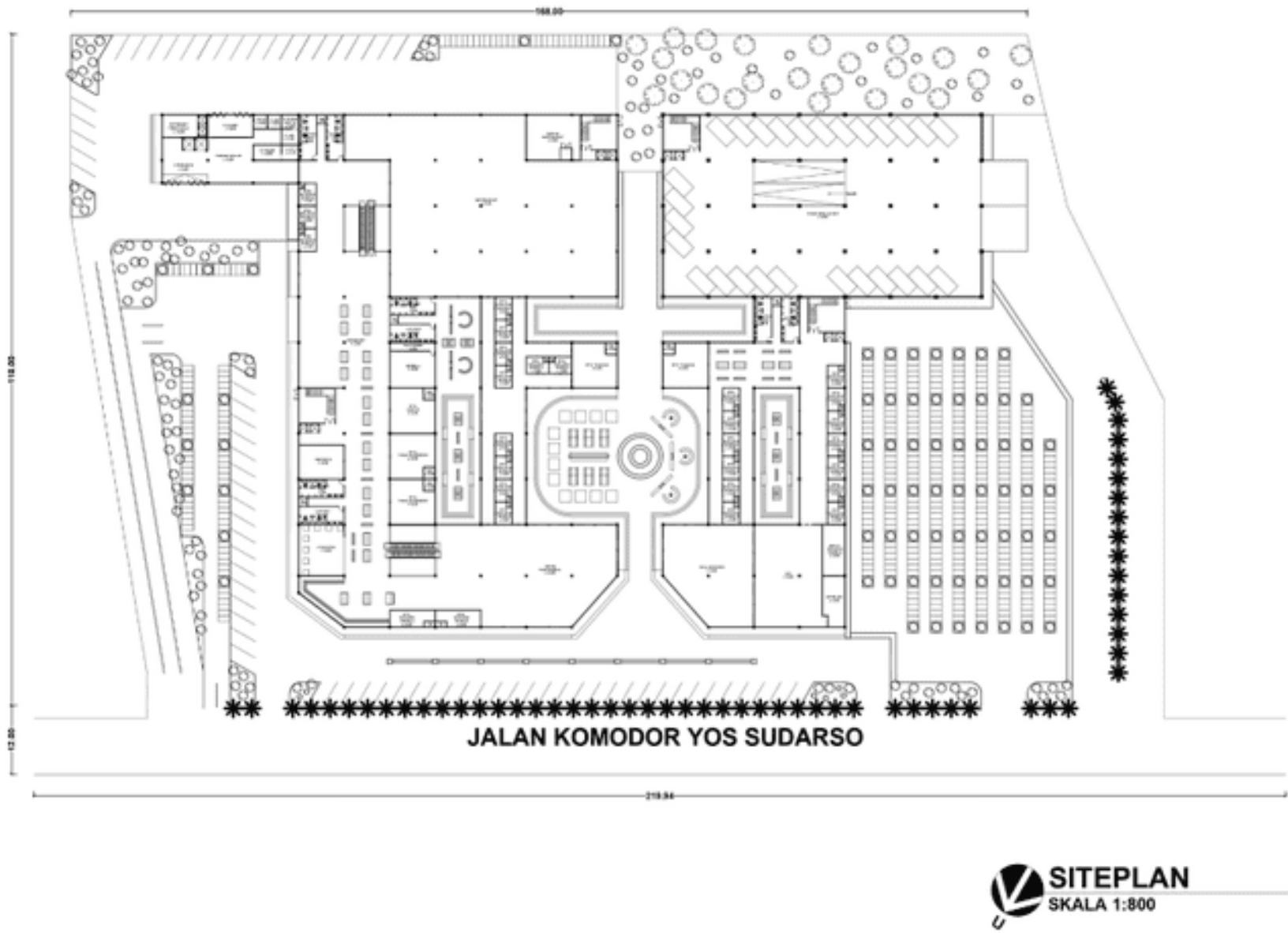

Gambar 8. Siteplan Pusat Perbelanjaan Modern di Kecamatan Pontianak Barat Sumber: Penulis, 2021

Tampak bangunan merupakan sebuah gambaran dari segala arah yaitu depan, belakang, kanan, dan kiri. Tampak juga memberikan informasi terkait tinggi, bentukan dan skala bangunan. 

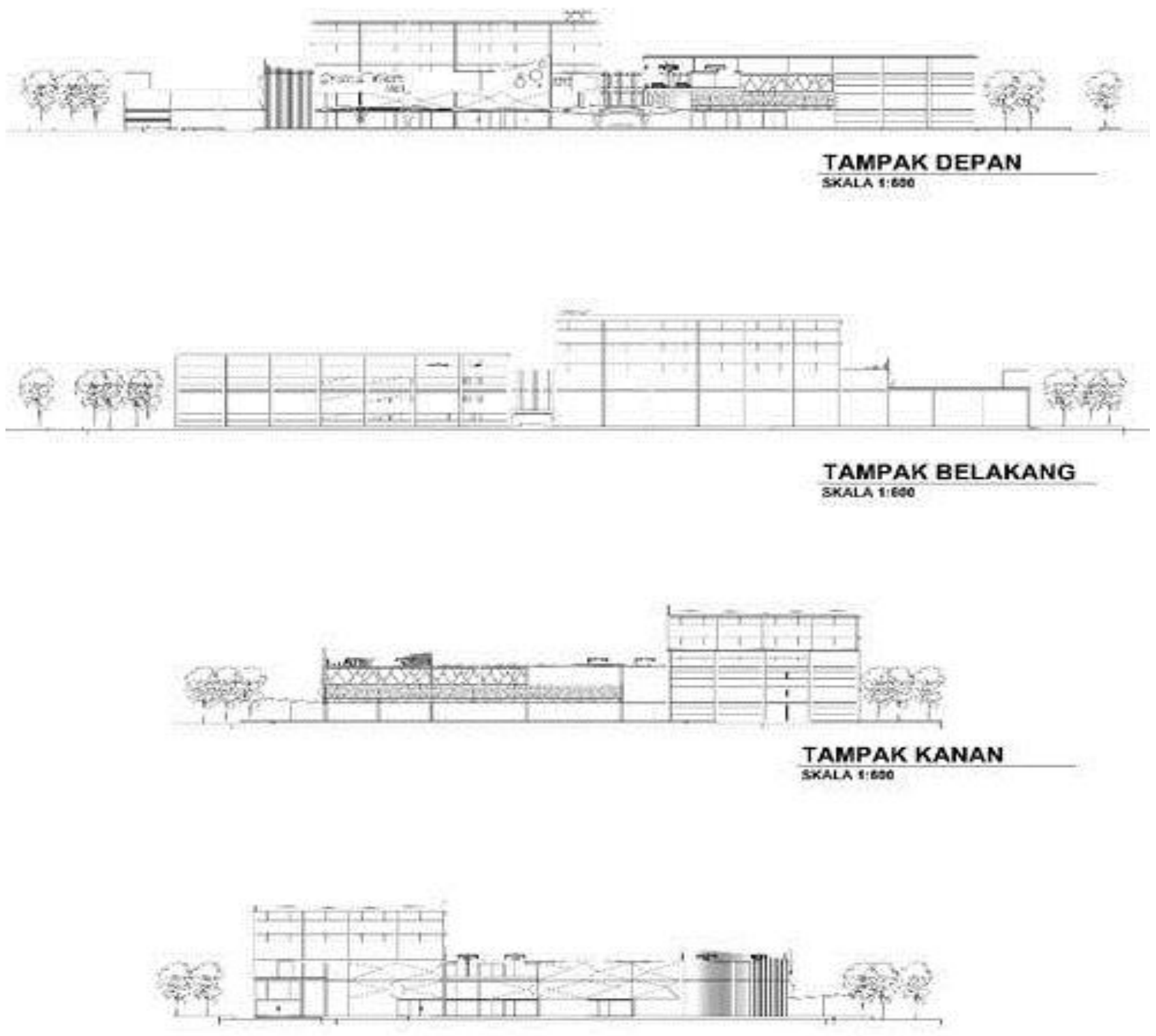

TAMPAK KIRI SKALA 1:690

Gambar 9. Tampak Pusat Perbelanjaan Modern di Kecamatan Pontianak Barat Sumber: Penulis, 2021

Suasana bangunan dibagi menjadi 2 jenis yaitu eksterior dan interior. Eksterior bangunan Pusat Perbelanjaan Modern di Kecamatan Pontianak Barat menghadap jalan Komodor Yos Sudarso. Pusat Perbelanjaan Modern di Kecamatan Pontianak Barat ini terdiri dari dua massa bangunan yang dihubungkan dengan sky bridge, menggunakan fasad bentukan solid dan memberikan area rekreasi ditengah bangunan yang dimanfaatkan sebagai fungsi perbelanjaan dan komunal. 


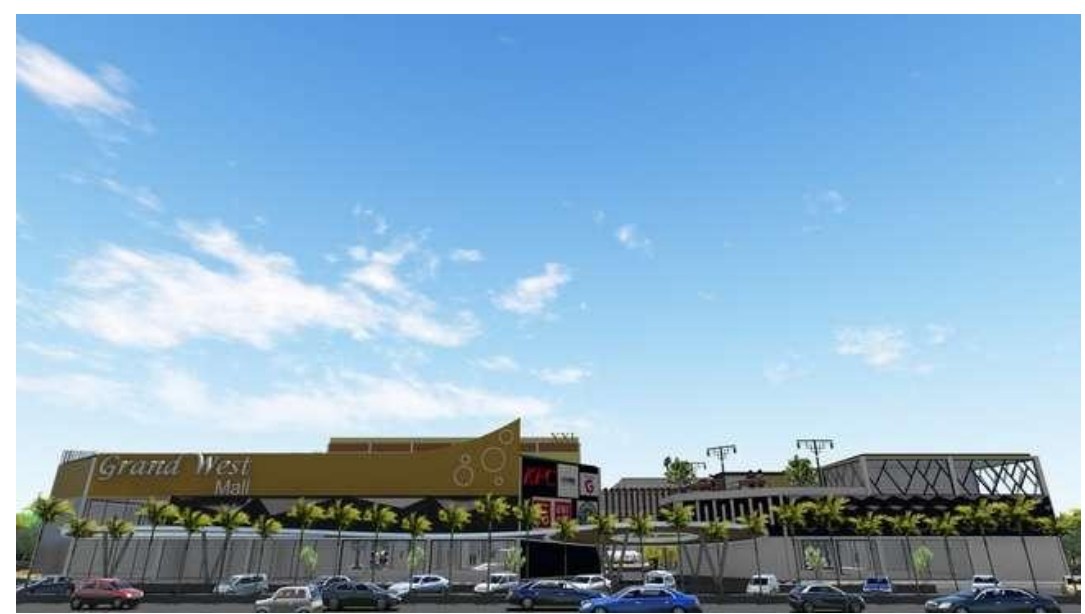

Gambar 10. Suasana eksterior Pusat Perbelanjaan Modern di Kecamatan Pontianak Barat Sumber: Penulis, 2021

Suasana pada gambar dibawah ini memperlihatkan bagian entrance bangunan dan area parkir mobil pengunjung.

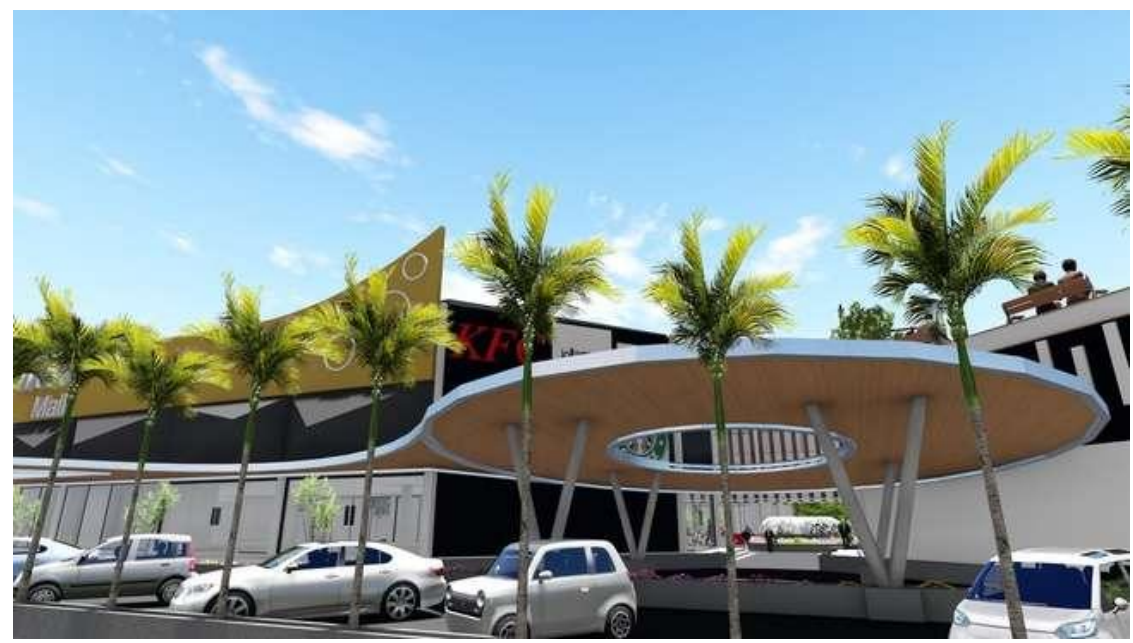

Gambar 11. Entrance Pusat Perbelanjaan Modern di Kecamatan Pontianak Barat Sumber: Penulis, 2021

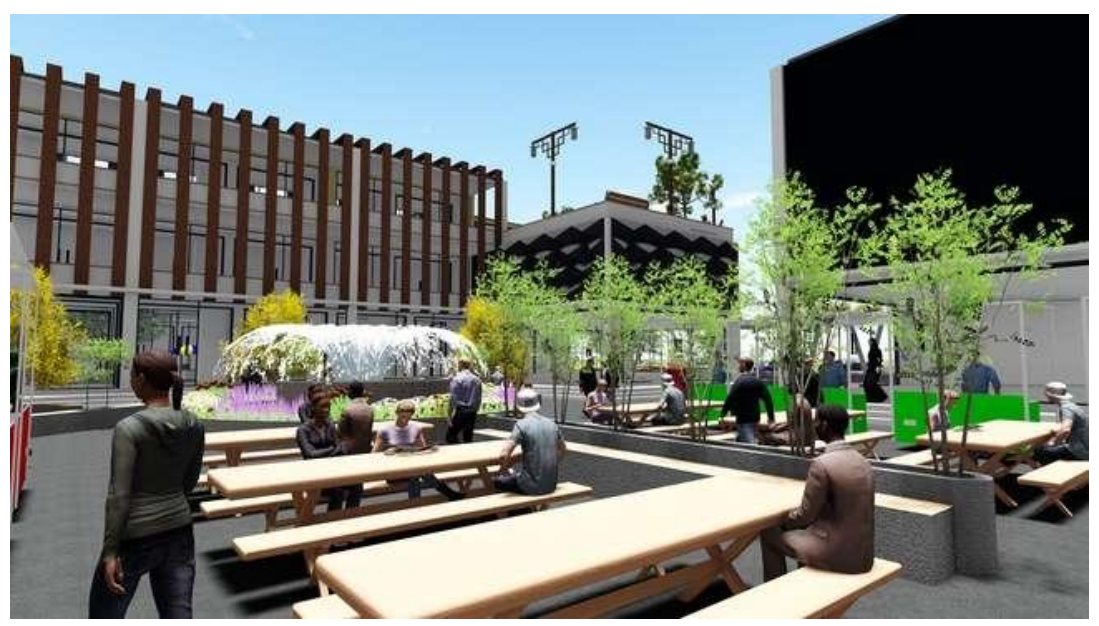

Gambar 12. Area Taman Pusat Perbelanjaan Modern di Kecamatan Pontianak Barat Sumber: Penulis, 2021 
Suasana interior memperlihatkan keadaan supermarket yang berada di lantai satu dengan akses berdekatan dengan area foodcourt. Kemudian memperlihatkan area kosmetik yaitu salon dan spa yang berada di lantai dua dengan menggunakan pola lantai parkit.

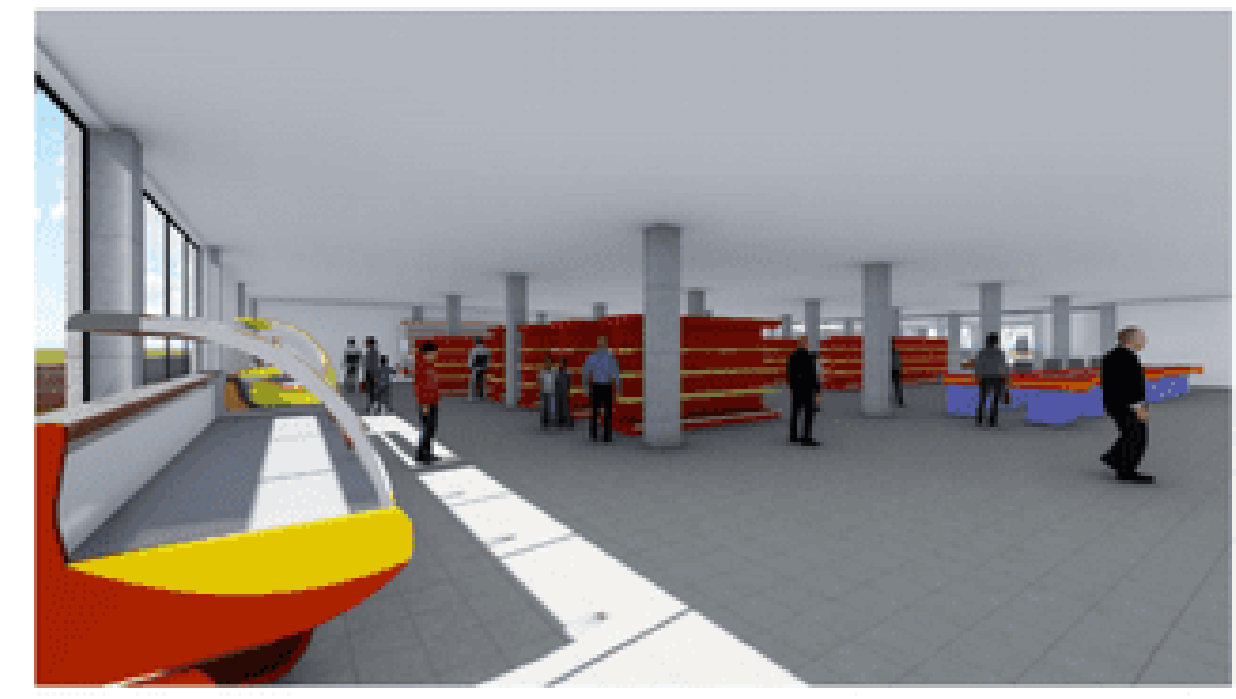

Gambar 13. Suasana Area Supermarket Sumber: Penulis, 2021

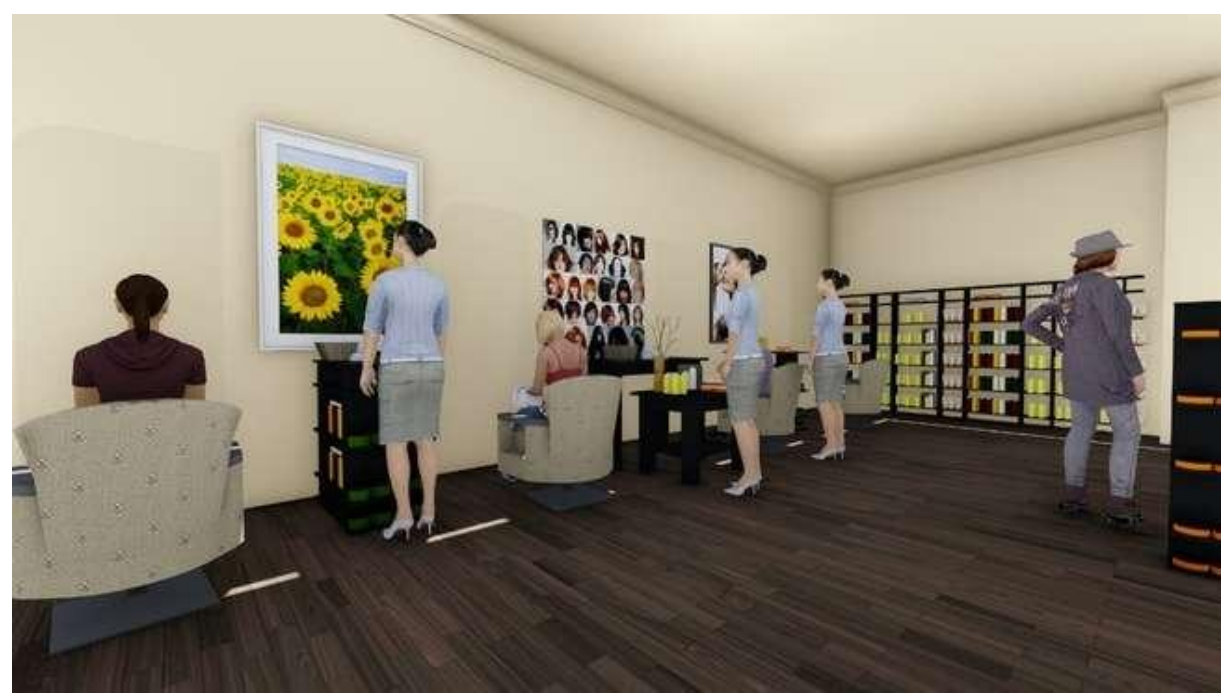

Gambar 14. Suasana Area Salon dan Spa

Sumber: Penulis, 2021

\section{Kesimpulan}

Dari hasil data yang telah melalui proses analisis dengan mencapai tujuan perancangan Pusat Perbelanjaan Modern di Kecamatan Pontianak Barat dengan konsep Open Mall. Pusat Perbelanjaan Modern ini memberikan area rekreasi dan hiburan, pusat perbelanjaan ini juga memberikan area ruang terbuka yang dimanfaatkan sebagai area perbelanjaan. Pada setiap lantainya memberikan sebuah magnet-magnet perbelanjaan seperti supermarket, department store, karoke, bioskop, area bermain dan fitness center.

\section{Ucapan Terima Kasih}

Kesempatan ini penulis memberikan ucapan syukur kepada Allah SWT dan terima kasih kepada keluarga yang telah memberikan dukungan penuh terhadap proyek tugas akhir ini. Penulis 
juga mengucapkan terima kasih kepada dosen pembimbing yang telah memberikan bimbingan dalam proyek tugas akhir. Serta ucapan terima kasih kepada teman-teman dan pihak yang telah terlibat dalam proses penyelesaian proyek tugas akhir ini.

\section{Daftar Acuan}

Badan Pusat Statistik Kota Pontianak. (2018). Kecamatan Pontianak Barat Dalam Angka 2018. Pontianak: Badan Pusat Statistik Kota Pontianak

Fairchild, H.P. (1994). Dictionary Of Sosiology, Philosophical Library. Paterson, New Jersey: Littlefield, Adam \& Co Haryono, W. (1978). Pariwisata Rekreasi dan Entertaiment. Bandung: Ilmu Publisher

Kementerian Pekerjaan Umum Republik Indonesia. (2020, August 15). Peraturan Menteri Pekerjaan Umum Nomor 29 Tahun 2006 Tentang Persyaratan Teknis Bangunan dan Gedung. Retrieved from https://pustaka.pu.go.id/biblio/peraturan-menteri-pekerjaan-umum-nomor-29prtm2006-tentang-pedomanpersyaratan-teknis-bangunan-gedung/547DL

Maitland, B. (1985). Shopping Malls-Planing Design. New York: Langman Grup, Limited

Marlina, E. (2008). Panduan Perancangan Bangunan Komersial. Yogyakarta: PT. ANDI offset

Neufert, E. (1992). Data Arsitek Jilid Pertama. Jakarta: Penerbit Erlangga

Nuraini, C. (2010). Metode Perancangan Arsitektur. Bandung: Karya Putra Darwati

Rubenstain, H. M. (1978). Central City Mall. New York: A Willey-Interscience Publication

Sekretariat Negara Republik Indonesia. (2020, August 10). Peraturan Presiden Republik Indonesia Nomor 29 Tahun 2007 Tentang Penataan Dan Pembinaan Pasar Tradisional Pusat Perbelanjaan Dan Toko Modern. Retrieved from https://peraturan.bpk.go.id/Home/Details/42157/perpres-no-112-tahun-2007 